\title{
La falsa democracia del espacio público Geopolítica, producción discursiva y cartografías del poder en América Latina The false democracy of public space
}

Geopolitics, discursive production, and cartographies of power in Latin America

Carla Alexandra Felipe Narciso ${ }^{1}$

http://orcid.org/0000-0003-3177-8950

Primera versión recibida en: 04 marzo, 2020

Última versión recibida en: 27 agosto, 2020

\section{Resumen}

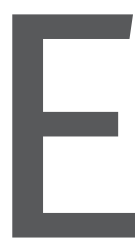

n los últimos veinte años, el concepto de espacio público se ha vuelto dominante tanto en los discursos gubernamentales como académicos, sobre todo en regímenes políticos progresistas y democráticos de América Latina, y eso por el arbitrio ideológico y abstracto de lo público, del orden democrático y de la opinión pública moderna, lo cual ha sido determinante como marco legitimador de prácticas geopolíticas y discursos hegemónicos que determinan un statu quo que ha permitido al sistema capitalista neoliberal seguir reproduciéndose a partir de las estructuras urbanas y el desarrollo urbanístico en contextos de dominación y dependencia. En este sentido, el presente trabajo procura (des)mistificar la conformación hegemónica occidental del concepto de espacio público (como ámbito de la filosofía² y esfera pública de deliberación política), desde la teoría crítica urbana y la teoría política feminista y cómo el mismo ha encontrado un territorio fértil de materialización discursiva y anclaje espacial de control y dominación de los países hegemónicos hacia Latinoamérica, reproduciendo un statu quo de colonización y explotación asociada a formas progresi-

1 Investigadora titular Centro de Investigaciones en Arquitectura, Urbanismo y Paisaje. Universidad Nacional Autónoma de México.

2 No es lo mismo hablar de espacio público que de espacio público urbano o espacios verdes urbanos, son conceptos distintos que no significan lo mismo, aunque muchas veces se usen como sinónimos.

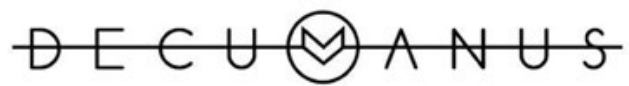

REVISTA INTERDISCIPLINARIA SOBRE ESTUDIOS URBANOS 
vas de politización teórica, a través de una trasnacionalización de la política, que se hace visible en los grandes proyectos de renovación urbana. Este trabajo se apoya de reflexiones teóricas, como marco analítico que permití hacer visible que el uso del concepto de espacio público no es neutral, pero está subsumido a una lógica política de legitimidad social y empoderamiento del capital hegemónico, y que ha tenido consecuencias espaciales, como una mayor segregación y fragmentación socioespacial, bajo un discurso democrático de "para todos", inclusivo y del bien común que ha perpetuado en la reestructuración de nuevas formas de control y dominación.

Palabras-clave: espacio público, falsa democracia, discursos ideológicos, geopolítica, cartografía del poder.

\section{Abstract}

In the last twenty years, the concept of public space has become dominant in both government and academic discourses, especially in progressive and democratic political regimes in Latin America, and this by the ideological and abstract abitrium of the public, democratic order and modern public opinion, which has been decisive as a legitimizing framework for geopolitical practices and hegemonic discourses that determine a statu quo that has allowed the neoliberal capitalist system to continue to reproduce from urban structures and urban development in contexts of domination and dependence. In this sense, this work seeks to (de)mystify the Western hegemonic formation of the concept of public space (as an area of philosophy and public sphere of political deliberation), from urban critical theory and feminist political theory and how it has found a fertile territory of discursive materialization and spatial anchoring of control and domination of hegemonic countries towards Latin America, reproducing a statu quo of colonization and exploitation associated with progressive forms of theoretical politicization, through a transnationalization of politics, which becomes visible in large urban renewal projects. This work is based on theoretical reflections, as an analytical framework that has made visible that the use of the concept of public space is not neutral, but this subsumed to a political logic of social legitimacy and the empowerment of hegemonic capital, and that has had spatial consequences, such as greater segregation and socio-spatial fragmentation, under a democratic discourse of "for all", inclusive and the common good, which has perpetuated the restructuring of new forms of control and domination.

Keywords: public space, false democracy, ideological discourses, geopolitics, power mapping.

\section{Introducción}

El concepto de espacio público es un concepto relativamente reciente que surge en los años setenta (sobre todo en documentos administrativos y de carácter estatal) y que emerge en los ochenta, tanto en el ámbito académico como político,

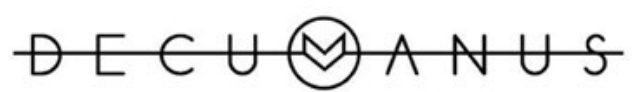

REVISTA INTERDISCIPLINARIA SOBRE ESTUDIOS URBANOS 
definido como el espacio democrático, universalista y plural, desvinculado del capitalismo económico global y como promesa de la posmodernidad y de gobiernos progresistas que abogan ideológicamente la libertad y transformación totalitaria y unificadora. En este sentido, el espacio público por su carácter de lo público como la posibilidad de representación igualitaria de un Estado que protege a sus ciudadanos, se vuelve un concepto dominante como formación discursiva de legitimidad política de los proyectos de renovación urbana, marco representacional de formas políticas de desarrollo, sobre todo en contextos de subdesarrollo como el caso de América Latina, en un periodo de giro a la izquierda y de emancipación de los proyectos de transformación urbana respaldados por formas de producción cultural y marcos identitarios de integración social. Así, el espacio público se ha vuelto un concepto de moda que se establece desde el ámbito de la filosofía política y configura un marco ideológico de una configuración pública donde se establecían las decisiones públicas (concernientes al Estado, o sea que tenían que ver con toda la sociedad) por decisores ilustrados, enmarcados en una configuración espacial. Esa disposición de lo público fue parte de las determinantes del urbanismo moderno (como discurso) y como elemento determinante de materialización ideológica en la posmodernidad y de una política global neoliberal, con particular incidencia en América Latina. Esto ha llevado a cuestionar: ¿Qué es el/lo/del público?, ¿cómo se ha construido la dimensión pública y de lo público en la actualidad en contextos de Latinoamérica?, ¿por qué se ha vuelto tan importante el ámbito de lo/del público en los discursos y procesos de subjetivación académicos y políticos de gobiernos neoliberales, dichos democráticos y progresistas?, y, ¿en qué medida la construcción del espacio público en América Latina se establece desde la universalización de una geopolítica disciplinar a través de un repliegue de condiciones de sometimiento socioespacial? Como respuesta a los cuestionamientos partimos de tres analogías constitutivas que permiten encausar la ruta crítica para descortinar la conformación teórica -política del espacio público, así como las implicaciones socioespaciales del uso de este. La primera es la construcción de una esfera pública en el siglo XVIII, que se diferencia de la privada y que constituye el ámbito de conformación y dominación de una sociedad capitalista burguesa moderna, así como un bien común; en segundo lugar, en la disipación de un discurso ideológico opresor que oculta las formas enajenadas de existencia bajo un régimen biopolítico de regulación y control a través de estructuras y mecanismos políticos y de poder que se visibilizan en el espacio público urbano; y finalmente, la tercera y última, en los marcos hegemónicos de una izquierda europea traducidos en las directrices de la planeación estratégica (Borja y Castells, 1997) -planeación empresarial, Harvard Business School-, y con particular incidencia en América Latina y el giro a la izquierda. De esta forma, el presente trabajo procura reflexionar, desde el marco analítico de la teoría urbana crítica y la teoría política feminista sobre las implicaciones socioespaciales del uso del concepto de espacio público (como práctica inherente a los procesos de subjetivación espaciales, que cuestiona la producción social del espacio y la configuración ideológica de una esfera pública democrática -que cuestiona la

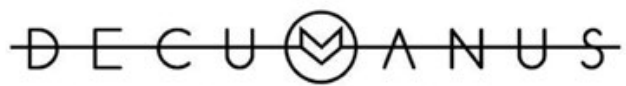

REVISTA INTERDISCIPLINARIA SOBRE ESTUDIOS URBANOS
Núm. 5. Vol. 5. Octubre 2019-Octubre 2020. Instituto de Arquitectura, Diseño y Arte.

Universidad Autónoma de Ciudad Juárez. ISSN: 2448-900X 
acepción de un estado que alguna vez fue democrático, plural e incluyente, para pasar a entenderlo como una apuesta de una estructura patriarcal subordinada que no considera las múltiples trayectorias y los actores) en la especialización de la conformación ideológica de la esfera pública y el traslape a la materialización de un espacio público, ensamblado en las prácticas políticas neoliberales y los procesos de subjetivación entendidos desde la crítica de la teoría política feminista, las relaciones de poder y la teoría urbana crítica en América Latina.

\section{Espacio público: la historia que no se cuenta}

El espacio público en los términos en que se conoce actualmente es un producto y productor de la sociedad capitalista moderna, cuyos valores son reivindicados por el proyecto neoliberal de un espacio público moderno, como una "tendencia civilizatoria dotada de un nuevo principio unitario de coherencia o estructuración de la vida social civilizada y del mundo correspondiente a esa vida, de una nueva 'lógica' que se encontraría en proceso de sustituir al principio organizador ancestral, al que ella designa como "tradicional"' (Echeverría, s/f). En el establecimiento de nuevas reglas y un nuevo orden socioespacial, el surgimiento de una sociedad capitalista burguesa moderna fue determinante para la demarcación entre la esfera del público y de lo privado, así como la constitución de una sociedad civil, en que se genera una privatización de un orden de la economía capitalista, como defensa del liberalismo clásico y, a su vez, una expansión y consolidación de la burguesía como clase hegemónica. "La burguesía no solo será la clase política y económica dominante, sino que impondrá un estilo de vida, un modo de ser, un sistema de valores; en fin, una cosmovisión que se expresará como la ideología dominante en la sociedad liberal-capitalista" (Ander-Egg,1998 :46). Esa imposición se da en el tránsito del feudalismo hacia el capitalismo, que procuraba el desarrollo dialéctico de la sociedad, en la cual las viejas relaciones de producción eran ya caducas de acuerdo al grado de desarrollo de las fuerzas productivas, y se encontraban en una indisoluble contradicción que únicamente podría ser superada a través de un proceso revolucionario que, en esa etapa histórica de la humanidad, le competía a la burguesía, como portadora del desarrollo social para la época.

Pero, ¿cuándo y cómo surge el concepto de espacio público en su relación espacial?, o sea en su relación con el urbano como forma de producción y anclaje de capital, desde y como ideología de la sociedad capitalista moderna occidental.

Según François Ascher (1995), el término de espacio público aparece por primera vez en un documento administrativo en 1977, en el cuadro de un proceso de intervención pública, que agrupaba en la misma categoría los espacios verdes, las calles, las plazas, la valorización del paisaje y el mobiliario urbanos. Sin embargo, el debate sobre el mismo fue iniciado (desde la esfera pública) mucho antes con las aportaciones desde la filosofía política de Hannah Arendt (1993), quien cuestionó el significado de lo público (desde una perspectiva más jurídica), como el lugar posible de la razón; y con Jürgen Habermas (1984), quien define la esfera pública como la posibilidad de integración de iguales en el ejercicio de la democracia.

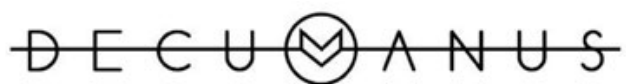

REVISTA INTERDISCIPLINARIA SOBRE ESTUDIOS URBANOS 
Las aportaciones desde la filosofía política de estos autores sobre la dimensión pública y privada del espacio se han convertido en uno de los marcos principales de discusión del espacio público. A pesar de que estos autores no hayan discutido el desarrollo del concepto de espacio público como tal, la conformación histórica con la que analizan la esfera pública se convirtió en un sello imperativo en el análisis del concepto como espacio de la ciudadanía y de la expresión igualitaria del poder y de los derechos comunes. Habermas (1984) y Arendt (1993) retoman la esfera pública y privada de la civilización griega y romana, configurada a partir del ágora y el fórum, donde el ciudadano libre y los señores feudales ejercitaban su poder. Así, los análisis de Habermas (1984) y Arendt (1993) han moldeado la acepción de un espacio público que es considerado como aquel que, siendo del uso común y posesión colectiva, pertenece al poder público y como tal existe para el uso de todos, dentro del territorio urbano tradicional, especialmente en las ciudades capitalistas donde la presencia de lo privado es predominante.

Estas dimensiones de análisis se trasladaron a un discurso que -según autores como Emilio Duhau y Angela Giglia (2008)- construyó una suerte de ideal que remite a un conjunto de atributos propios de los espacios públicos de la ciudad moderna, a saber: espacios asignados al uso del público, es decir, no reservados para nadie en particular. De esta forma, se identifica por espacio público todos los espacios que pertenecen a los diversos niveles de administración, Estado, comunidades autónomas o administración local, los cuales, por lo tanto, serán abiertos, administrados por los ciudadanos o el Estado, que es su representante. Esta relación y definición del espacio público a partir del privado es una constante en diversos estudios sobre el tema.

Los valores de la esfera pública son replegados al espacio público de las ciudades modernas, sobre todo, en los países industrializados, en donde se defiende la necesidad de construir espacios controlados o, como menciona Peter Baldwin (1999), espacios domesticados donde todo tiene un orden y una "posición", a partir de los valores morales del espacio doméstico de las clases ilustradas. Se trata de la proyección a la esfera del espacio público urbano de valores morales $y$, con ello, de la disciplina y la organización de la calle y de sus usuarios pertenecientes a las clases populares, de acuerdo con dichos valores (Duhau y Giglia, 2008). Aquellos se hicieron efectivos en el poder que las nuevas clases burguesas adquirieron, el cual también se reflejó en un nuevo orden socioespacial y en la reproducción de la fuerza de trabajo. Sin embargo, hubo elementos que más tarde permitieron "abrir" o democratizar los espacios públicos, principalmente en los países occidentales a partir de una política o modelo de Estado y de organización social que aprovisionaría diversos servicios a todos los habitantes de un país (como vivienda pública, salud y educación).

En el caso de la arquitectura, la influencia arendtiana resurge en la espacialización de los discursos (como espacio de la acción), donde gobierna el dominio de la forma sobre las relaciones sociales. Así, el espacio público termina de ser un elemento estructurador y vertebrador del territorio de la ciudad y se convierte en el espacio físico que se moldea en principios estéticos de organización eco-

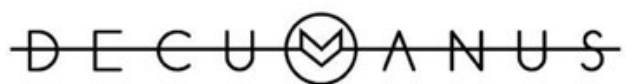

REVISTA INTERDISCIPLINARIA SOBRE ESTUDIOS URBANOS
Núm. 5. Vol. 5. Octubre 2019-Octubre 2020. Instituto de Arquitectura, Diseño y Arte.

Universidad Autónoma de Ciudad Juárez. ISSN: 2448-900X 
nómica. Pero aquella conformación ideológica (neutral, estática y totalizadora) se ha vuelto clave en las discusiones académicas de autores como Richard Sennett (1978), Jordi Borja (2003), Angela Giglia (2003), Sharon Zukin (2010), Patricia Ramírez Kuri (2009), entre otros tantos de distintas latitudes geográficas y disciplinarias, en que el espacio público sigue siendo construido como elemento activo en la comprensión de las relaciones y prácticas sociales que espacializan, transformando, por un lado, la estructura, la forma y la imagen urbana, y por otro, las actividades humanas y el significado de la ciudad vivida por grupos y actores sociales diferentes. En estos discursos el espacio público surge por excelencia de y en la ciudad; es el espacio a partir del cual se conoce la ciudad, como un lugar de representación y de expresión colectiva de la sociedad (Borja, 2003), a lo cual se vinculan valores como: libertad y de cohesión social, protección y desarrollo de los derechos individuales, expresión y construcción de identidades colectivas, democracia participativa y de igualdad básica entre sus habitantes) depende de que el estatuto de ciudadanía sea una realidad material y no solamente un reconocimiento formal. A su vez, según el autor (Borja, 2003) el espacio público constituye un factor importante de identificación que define los lugares y se manifiesta mediante símbolos, y lo define, así como el lugar de la palabra, como lugar de socialización, de encuentro donde también se manifiestan y expresan grupos sociales, culturales y políticos de la población de la ciudad. Francesco Indovina (2002), al igual que Borja (2003), reivindica la ciudad como espacio público, y se niega a atribuirle solamente un uso especializado único, y concuerda en que "es la ciudad en su conjunto que merece la consideración del espacio público" (Borja, 2003: 46); es decir, que este es el lugar por excelencia de la socialización. Sin embargo, la definición de Borja (2003) parece algo idílica, si la pensamos desde la propia conformación histórica del concepto y la crítica desde la teoría política feminista. Da la impresión de que el espacio público sería el lugar donde el ciudadano tiene derecho a circular, a estar y hacer, en contraste con el espacio privado donde el paso, la estancia y la acción están restringidas. Peter Goheen (1998), al igual que otros autores, marca el análisis del espacio público a partir de dos respetuosas valorizaciones que contrastan entre sí acerca del significado del espacio público. Por un lado, retoma la idea de Richard Sennett (1978) en cuanto a que la esfera pública ha sido radicalmente devaluada como un poderoso ideal social y político en la ciudad moderna; por otro, refiere a Sharon Zukin (2010), quien refuta que es en el espacio público donde se celebra la vida urbana pública, además que las características que definen el espacio público en estas condiciones son la proximidad, la diversidad y la accesibilidad, al igual que lo plasma Serpa (2004). Parece, así, que se encuentra con el espacio público para todos. Pero, ¿de qué vida pública colectiva se habla en su conformación espacial, la construida bajos los principios modernos de la ordenación de una esfera pública burguesa capitalista? La vida urbana se celebra a partir de la interacción entre todos los grupos sociales y no de unos cuantos, porque los mismos principios de la modernidad marcaban una vida urbana controlada y fragmentada por grupos sociales.

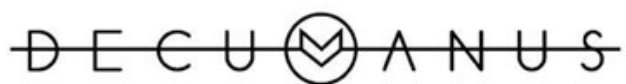

REVISTA INTERDISCIPLINARIA SOBRE ESTUDIOS URBANOS
Núm. 5. Vol. 5. Octubre 2019-Octubre 2020. Instituto de Arquitectura, Diseño y Arte.

Universidad Autónoma de Ciudad Juárez. ISSN: 2448-900X 
Esta perspectiva -más allá de la diferencia entre público y privado- cuestiona la validez de mirar el espacio público actual como un repliegue perdido de la modernidad, ya que la extensión de análisis de la filosofía política fue sobredimensionada en un ideal que no existe o, mejor, que nunca existió, lo cual ha sido bien desarrollado desde la teoría política feminista (Fraser, 1991). Desde la base teórica-metodológica que se asume en el presente trabajo (teoría urbana crítica), se considera que es a partir de este marco interpretativo, analítico y epistemológico que surgen las principales aportaciones que han permitido cuestionar la incursión de la esfera pública de Habermas -como marcas de distinción a la racionalidad dialógica de los hombres blancos y burgueses (Fraser, 1991)- en la conformación de un ideal de espacio público, que han disipado las acciones de gobiernos supuestamente democráticos. En este sentido, se ha cuestionado el espacio público del ágora, de la democracia y del derecho como si no existiera, porque la política no siempre es democrática $y$, aunque lo fuera, no todos participan como iguales, sobre todo en América Latina. El proyecto de la modernidad se caracteriza por la disociación entre esfera pública y privada, espacios de convivencia social que existían desde la antigua Grecia. Esta separación es la que permite, en gran medida, la opresión de las mujeres en las sociedades modernas, ya que se encuentra construida sobre un sistema de exclusión sexo/género que asocia la esfera pública a los hombres, mientras que relega a las mujeres a la esfera privada (Medina-Vicent, 2013). Así, aunque las mujeres nunca hayan sido completamente excluidas de la vida pública "su modo de estar en ella estaba anclado en su posición en la vida privada" (Beltrán, 1994).

Además de esta forma de discurso como signo de distinción, la sociedad civil que componía la esfera pública surgió por oposición a la esfera doméstica. Lo "doméstico" fue caracterizado como el espacio de práctica de las normas naturales; acuñando lo "natural", en esta acepción, a lo ajeno a la historia, y, por lo tanto, aquello que no es concebible como transformable y político. Al respecto, cabe mencionar los aportes de Iris Marion Young:

El mundo burgués instituyó una división moral del trabajo entre razón y sentimiento, identificando la masculinidad con la razón y la feminidad con los sentimientos, el deseo y las necesidades del cuerpo. Ensalzar un ámbito público de virtud y ciudadanía masculina como independencia, generalidad y razón desapasionada conllevó la creación de una esfera privada de la familia entendida como lugar en que debían confinarse las emociones, sentimientos y necesidades corporales (Young, 1996: 99).

Por una parte, si la esfera pública requiere de la dicotomía de lo público y lo privado, buscar su reproducción implicaría, en esta perspectiva, asumir y defender esta dicotomía (Andreoli, 2014). Por otra, en su conformación de una esfera pública, Habermas (1984) plantea que los individuos, al someterse a la exigencia de la racionalidad dialógica, necesariamente se asumen como iguales, en este sentido surge la segunda crítica de Fraser (1997), enmarcada en los principios del

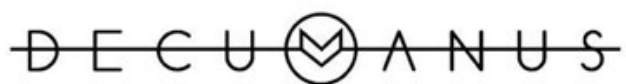

REVISTA INTERDISCIPLINARIA SOBRE ESTUDIOS URBANOS 
marxismo, ya que la forma de emancipación propuesta por el liberalismo, además de falsa, colaboraría en reproducir las desigualdades sociales, puesto que las invisibiliza al proponer su superación en una forma enajenada de existencia (Andreoli, 2014).

En cuanto a la suspensión de la desigualdad social solo, durante la deliberación significa proceder como si no existiera, cuando en realidad está presente y el modelo no promueve la paridad en la participación. Por el contrario, dicha suspensión usualmente obra en ventaja de los grupos dominantes en la sociedad y en desventaja de los subordinados. En la mayoría de los casos sería más apropiado suspender las desigualdades, en el sentido de discutirlas explícitamente (Pratt, 1999), ya que eso legitima la actuación gubernamental, pues oculta las diferencias sociales. Asimismo, Nancy Fraser (1997) cuestiona que haya una esfera pública única, ya que la autora considera que conviven múltiples esferas, generadas por la próxima exclusión de una hegemónica que controla las demás.

En este contexto importa hacer un paréntesis, ya que en el periodo contemporáneo se dan diversos acontecimientos (por ejemplo, el movimiento por los derechos civiles de los afroamericanos, el movimiento gay, la caída del muro de Berlín) que muestran cómo los grupos "excluidos" encuentran en el espacio público una forma de reivindicación de sus derechos en oposición a la idea de la ciudad controlada. Estos acontecimientos revelan una sociedad más compleja y poco lineal, así como más activa. Por un lado, la reivindicación de algunos grupos excluidos que muestran sus demandas en el espacio público empieza a definirlo como el espacio del conflicto (porque es el espacio de negociación entre los distintos sujetos-narradores de las historias contemporáneas). No obstante, por otro, cabe destacar que, aunque desde la modernidad hay quien mencione que los derechos ganan otra visibilidad y que empiezan a ser reconocidos, el hecho es que ese reconocimiento pasa por su incorporación al propio circuito de producción de capital, ocultando una serie asimetrías sociales. A grandes rasgos, podría decirse que este reconocimiento se integra a la hegemonía ideológica y no representa una toma de conciencia significativa para el resto de la población.

Así, el espacio público gana nuevos elementos de definición porque se convierte simultáneamente en un elemento de orden y de caos. En términos de orden se define a partir de dos posiciones: una en que la localización espacial de los fenómenos es causada y otra en la que el espacio es, en sí mismo, un sistema organizado que tiene una posición. Como elemento de caos, el espacio es necesariamente conflictivo porque en él se da la construcción de las identidades que, de acuerdo con Pratt (1999), es siempre excluyente debido a que las identidades emergen de la geografía histórica del conflicto y de la diferencia, y esa geografía en sí misma trabaja para estabilizar identidades. Pratt (1999) y Massey (2005) retoman el conflicto a partir del marxismo, para el cual las relaciones sociales son siempre de conflicto, de pertenencia a una de ellas y esto es lo que genera las relaciones.

Cabe recordar que el modelo democrático pluralista -que desde la década de los ochenta es objeto de un consenso en Europa como nunca lo había sido en la historia- fue considerado entre 1930 y 1977 como un concepto de "derecha" por

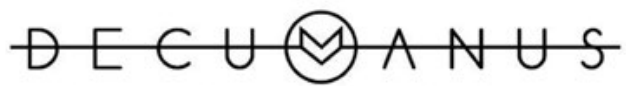

REVISTA INTERDISCIPLINARIA SOBRE ESTUDIOS URBANOS
Núm. 5. Vol. 5. Octubre 2019-Octubre 2020. Instituto de Arquitectura, Diseño y Arte.

Universidad Autónoma de Ciudad Juárez. ISSN: 2448-900X 
el peso del marxismo, la Guerra Fría y las oposiciones ideológicas. Se oponía a la democracia "formal", burguesa, a la democracia "real", más o menos socialista. Y en esta amarga batalla ideológica nadie hablaba del espacio público. Las palabras dominantes del vocabulario político eran poder, conflictos, contradicción, intereses de clase, alienación, ideología. Pero, ¿de qué espacio público de reivindicación de derechos hablamos, cuando en muchos países los ciudadanos sufren fuertes represalias por manifestarse en el espacio público?

Parece ser así una concepción difícil, frente a una sociedad tan compleja y un espacio público que se resignifica de cara a una sociedad "supuestamente democrática", pero que en realidad es altamente controlada y dominada, que además como bien menciona Foucault (2004), ha establecido mediante la regulación de la vida cotidiana por el poder, que a su vez se puede entender a partir de una política de escalas.

En este sentido, se está de acuerdo con el análisis de Harvey (1985) para quien el espacio (y lo establecemos desde lo público) no es un objeto inanimado dentro del cual se desprenden los procesos sociales, sino cosas que los contienen del mismo modo en que son espaciales. Las contribuciones de Paulo Gomes (2002) en estudios recientes, también han mostrado la integración de las dinámicas y prácticas sociales con la configuración física para la comprensión del espacio público desde una perspectiva geográfica.

¿Entonces de qué espacio público se habla? No deja de ser oportuno pensar sobre estos supuestos teóricos y conceptuales, incluso porque se insiste en una crisis del espacio público que no puede ser debatida si no cuestionamos la historia del espacio público. No obstante, también hay que tomar en cuenta que el sentido del concepto cambia y se modifica de acuerdo con los contextos geográficos, aunque opera bajo las mismas lógicas y estrategias (o microestrategias) de poder. Por su parte, es importante tener presente cómo esa conformación ideológica se fue perpetuando en el espacio-tiempo en las distintas escalas geográficas, a partir de usos, apropiaciones, transformaciones y la percepción que la sociedad -en sus diferentes latitudes geográficas- tiene actualmente del espacio público, pero también cómo se ha construido desde el poder político y las implicaciones sociales del mismo.

Mencionar estas perspectivas no tuvo como objetivo mostrar con exhaustividad las condiciones de análisis, sino rescatar y utilizar elementos de su argumentación para dar cuenta de lo que representa uno de los principales problemas que caracterizan actualmente el espacio público, ya en las ciudades contemporáneas en América Latina, ya en los discursos académicos y políticos: la carencia de perspectivas empíricas de análisis del concepto y su construcción frente a las diferencias geográficas. Sobre todo, considerando la imposición de un modelo que proviene de la modernidad capitalista y que se ha perpetuado como modelo hegemónico de reproducción socioespacial a partir de distintos mecanismos y objetivos de poder espacializado en los lugares en un contrato social de derecho, o sea, un contrato de dominación.

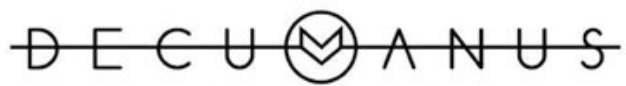

REVISTA INTERDISCIPLINARIA SOBRE ESTUDIOS URBANOS 


\section{Entre el público moderno y lo público urbano neoliberalizado: la ideología que se materializa}

Como cualquier ideología en el sentido de dominación (Althusser, 1980), necesita ser materializada, en el espacio (Soja, 2009) y a través de la infraestructura (Cowen, 2014), por lo cual se ha vuelto tan importante en la nueva política neoliberal, ya que en su construcción como espacio democrático, igualitario y expresión de la sociedad civil, ha permitido encabezar una agenda de transformación urbana -"a partir de las crisis geoeconómicas de comienzos de los setenta [...] las ciudades se han convertido en ruedos estratégicamente decisivos donde se han estado desplegando las formas neoliberales de destrucción creativa" (Theodore, et al., 2008)-, legitimada por el desarrollo y progreso que el urbano produce como espacio de todos.

En ese sentido, se instituyen (en el proyecto neoliberal) los principios del urbanismo moderno y que se caracterizan discursivamente por los marcos que permiten generar procesos hegemónicos de dominación, como los lemas de orden y progreso, libertad y desarrollo, espacializados en distintas premisas del diseño urbano, como lo es la domesticación de la calle, clara separación entre el espacio privado y el espacio público, uso intenso de este último como espacio libre tránsito, recreativo, de circulación y de acceso directo de las ofertas de consumo muy similar a las formas de planeación tradicional, aunque también estratégica de la zonificación o espacios zonificados. Así, la ciudad y su "espacio público"3 se convierte en centro neurálgico de la conformación del poder de clase, a través de un proyecto político llevado a cabo por la clase capitalista corporativa que se sentía profundamente amenazada, tanto política como económicamente hacia finales de la década de los sesenta y en los setenta (Harvey, 2007).

Lo que esta clase quería era implantar desesperadamente un proyecto político que pusiera freno al poder del trabajo a través de una política que afirma que los mercados abiertos, competitivos, no regulados y que no se encuentren sometidos a formas de intervención del Estado representan el mecanismo óptimo para el desarrollo económico. Este discurso preparó el terreno para justificar, entre otros aspectos, la desregulación del control estatal de las industrias principales, el desmantelamiento de las organizaciones de trabajadores, en particular los sindicatos, la reducción de los impuestos a las grandes y medianas empresas, la privatización de los servicios públicos, el desmantelamiento de los programas de bienestar, la ampliación de la movilidad internacional del capital, la intensificación de la competencia entre localidades y la criminalización de la pobreza urbana. La idea que subyace a todo esto es la hipótesis de que la liberación de ataduras del capital volvería a poner en marcha el sistema, tornando al proceso de acumulación y resolviendo la crisis. Dentro de este conjunto de prácticas, las

3 Cabe mencionar que, aunque se mencione como espacio público en términos del proyecto neoliberal, el hecho es que este se menciona desde la ideología y desde el mismo proyecto, ya que hay una materialización de esa ideología que se denomina espacio público en el urbano.

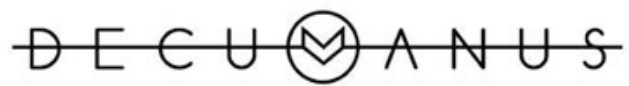

REVISTA INTERDISCIPLINARIA SOBRE ESTUDIOS URBANOS 
ciudades tienen una especial consideración como espacios para la obtención de rentas. A la forma más clásica, aquella vinculada al suelo y al urbanismo (Harvey, 2007), habría que añadir todas aquellas relacionadas con el papel de la ciudad como escenario de la reproducción social. De esta forma, la ciudad se convierte en un instrumento útil para la formación de capital. La urbanización habría llegado a sustituir a la industrialización en la producción de capital, lo que la convierte en uno de los principales determinantes de los procesos sociales (Lefebvre, 1978). Así, la construcción de la ciudad y de nuevas formas urbanas se adaptan a la compresión del espacio-tiempo impulsada por el capitalismo tardío a partir de la aceleración de los procesos económicos, la creciente mercantilización de la vivienda, los símbolos culturales la transformación misma de la experiencia subjetiva de su producción y reproducción de la sociedad. Todo ello, a partir de una transnacionalización de las formas de hacer ciudad -modelos impuestos por la economía hegemónica de los países capitalistas, incorporada a la escala local a partir de nuevos instrumentos políticos e idearios hegemónicos.

\section{Cartografías del poder en América Latina desde el espacio público}

La Gran Depresión de 1929, que fue percibida como una reacción crítica al éxito alcanzado por las propuestas keynesianas en EUA, las propuestas socialdemócratas en Europa y las teorías desarrollistas en América Latina, fue el momento clave que permitió conformar los "nuevos" marcos geopolíticos de regulación y flexibilización de los mercados neoliberales, donde las estructuras urbanas se volvieron imperativas para la acumulación del capital, sin que eso a su vez haya propiciado contracciones socioespaciales, ya que presuponía la organización de la sociedad desde una perspectiva espacial capaz de fijar y controlar a los individuos. Esto con el objetivo inmediato de "abrir nuevas oportunidades de mayores ganancias, para encontrar nuevas maneras de mantener el control social, y estimular los incrementos en la producción y el consumo" (Soja, 1989).

América Latina como territorio experimental y de reserva (humana, natural y económica) de la hegemonía capitalista se ha construido bajo sistemas de reproducción antagónicos de legitimación de los mismos grupos dominantes, quienes han sido los constructores de la misma izquierda, la cual a su vez se ha enclaustrado en discursos progresistas hegemónicos, que han servido a un mayor control y dominación geopolítica. Esto sucedió con especial incidencia a partir de los años ochenta, cuando comenzó la discusión sobre un giro a la izquierda. Dicho de otra manera: "luego de la transición desde las dictaduras en los ochenta y el peso de las reformas estructurales neoliberales de los noventa (la doble transición), parece registrarse entre los nuevos gobiernos un sesgo progresista o popular, que ha sido registrado bajo el rótulo de giro a la izquierda" (Francisco Cantamutto, 2013: 1). Pero, las preguntas que surgen ante este panorama son: ¿qué ha representado en realidad el giro a la izquierda? y ¿cómo se identifican los cambios en términos socioespaciales del "giro a la izquierda" en América Latina? En este sentido, es cada vez más difícil entender lo que denota el término desde que el grueso de

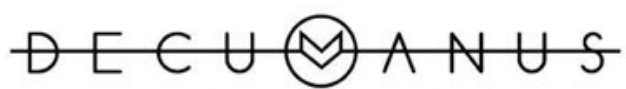

REVISTA INTERDISCIPLINARIA SOBRE ESTUDIOS URBANOS 
los partidos socialistas y las organizaciones de centroizquierda comenzó a dejar de lado sus resistencias a la economía de mercado y a desechar paulatinamente el lenguaje de la lucha de clases, la liberación nacional, el internacionalismo, la soberanía westfaliana estricta y demás (Arditi, 2009: 233).

Aun cuando de un discurso que procura un corte y ruptura con las políticas neoliberales y aun cuando se reconoce el desarrollo de las políticas sociales como el caso de Brasil cuando estaba Lula con el programa fome cero y que beneficiaron algunos sectores empobrecidos de la sociedad brasileña (Sierra, 2011)-, se reconoce que se produce una continuidad con las mismas. Por esa razón, es posible analizar cuatro narrativas que se reconocen como la base discursiva de esa secuencia y de una ruptura ideológica: la recuperación y fortalecimiento del Estado, las políticas de intervención, la intervención estatal para crear las condiciones de una agricultura mercantil, y las políticas sociales.

De forma sutil (deliberada o inconscientemente) los distintos gobiernos en América Latina -sobre todo en las principales capitales, como São Paulo, Santiago de Chile, Buenos Aires, Bogotá, San José y Ciudad de México- han incorporado a sus sistemas de planeación las directrices internacionales como parte de una pertenencia ideológica al circuito de ciudad global. Sin embargo, más que traer beneficios hacia dentro, generó una capitalización en los grupos de poder hacia afuera. Esto ha aumentado problemas socioespaciales, sobre todo, la pobreza en las ciudades (tabla 1).

Tabla 1. América Latina (1970-1997): evolución de la pobreza urbana

\begin{tabular}{|c|r|r|r|r|r|r|}
\hline Población pobre & \multicolumn{1}{c}{1970} & \multicolumn{1}{c}{1980} & \multicolumn{1}{c}{1986} & \multicolumn{1}{c}{1990} & \multicolumn{1}{c}{1994} & \multicolumn{1}{c|}{1997} \\
\hline Total & 119800 & 135900 & 170200 & 200200 & 201500 & 204000 \\
\hline Urbana & 44200 & 62900 & 94400 & 121700 & 125900 & 125800 \\
\hline Rural & 75600 & 73000 & 75800 & 78500 & 75600 & 78200 \\
\hline $\begin{array}{c}\text { Urbanización } \\
\text { de la pobreza }\end{array}$ & 36.9 & 46.3 & 55.5 & 60.8 & 62.5 & 61.7 \\
\hline
\end{tabular}

Fuente: Cepal (1994b y 1999)

A su vez, la forma de construir una base discursiva que busca instaurar y constituir los derechos, vincular las minorías, establecer una política social y un sistema democrático (con un valor diferenciado) es propia de los gobiernos de izquier$\mathrm{da}$, y que subyace cierta resistencia con las élites. En este sentido, los gobiernos de izquierda fácilmente incorporaron a su política gubernamental la planeación estratégica, en donde el espacio público fue el elemento ideológico que permitió establecer un marco de actuación diferencial, ensamblado en la narrativa de la democracia liberal proveniente del siglo de las luces y de la representación espacial de una sociedad capitalista burguesa.

Como parte de la restructuración política que enmarca los distintos ciclos económicos, los conceptos y las teorías se vuelven parte fundamental de la legitimidad, el control y la dominación de los países desarrollados en relación con los

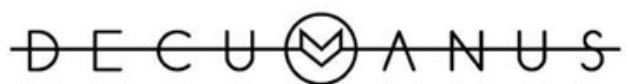

REVISTA INTERDISCIPLINARIA SOBRE ESTUDIOS URBANOS 
subdesarrollados, debido a la carga ideológica que transportan en su devenir de grupos "progresistas" hegemónicos. Sobre todo, en un periodo geopolítico neoliberal, la conformación ideológica de los conceptos es determinante, porque son adaptados a los distintos objetivos políticos, construidos bajo una intersubjetividad que se transforma de acuerdo con los momentos, lo cual neutraliza su concepción histórica y los vuelve estáticos. Esto posibilita la estatización de los procesos socioespaciales.

En este sentido, el espacio público ha destacado en las agendas políticas como concepto legitimador de políticas sociales y la narrativa democrática. Lo anterior se debe a la carga ideológica que el espacio público ha arrastrado a partir de los años ochenta, ensamblando los trabajos de Hannah Arendt y Jürgen Habermas en los marcos teóricos de la filosofía política, que han sido determinantes en la reestructuración de las nuevas formas de acumulación de capital, aunado a lo que Neil Smith (2005: 59) define del "nuevo urbanismo"; es decir, un urbanismo que implica la reestructuración de los Estados-desregulación y descentralización. Claramente esto no ha sido una determinante desde América Latina, pero sí una producción que se construyó desde las hegemonías capitalistas, implementada con el apoyo de las distintas "agencias multilaterales (BIRD, ONU-HABITAT) y consultores internacionales" (Vainer, 2000).

Como parte de toda la estrategia de cambio a partir de la reestructuración urbana capitalista, el espacio público adquiere un papel determinante, pluralista e integrador, como espacio de la democracia y empieza a integrar las agendas políticas gubernamentales en América Latina a distintas escalas. Por supuesto, esa incorporación no es neutral, porque es una forma de imposición, de entrada y sumisión de los estados hegemónicos a los países subdesarrollados en una forma de explotación socioespacial. Esto ha implicado dos procesos simultáneos. Por un lado, la despolitización política de la teoría cuando esta parece neutralizar los procesos socioespaciales, ya que se aboca a la representación de un término común, pero que expresa una interpretación errónea. Y, por otro lado, a su vez ese mismo proceso se puede visualizar como caso de extrema politización, ya que los conceptos y la teoría son utilizados como mecanismos políticos de control y dominación socioespacial.

Esta conformación ideológica contradictoria representa un ideal que ha generado formas hegemónicas de reproducción mediante mecanismos de dominación y empoderamiento con consecuencias adversas en América Latina. Más que formas discursivas del espacio público, los distintos mecanismos geopolíticos conforman espacios de desigualdad debido a la creación de infraestructuras sociales y físicas que respaldan la circulación de capital, que permite que la vida cotidiana se reproduzca eficazmente. Sin embargo, al contrario de lo que comenta Emilio Pradilla (2009: 525), que "bajo esta idea de modernización, las ciudades materializan las premisas neoliberales a través de "determinados mecanismos y patrones de acumulación sin importar cómo se autodenominen los poderes públicos, de izquierda o derecha", a través de formas arquitectónicas-urbanas que han provocado niveles de exclusión y de privatización de lo público a partir de nuevas

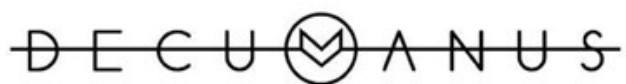

REVISTA INTERDISCIPLINARIA SOBRE ESTUDIOS URBANOS
Núm. 5. Vol. 5. Octubre 2019-Octubre 2020. Instituto de Arquitectura, Diseño y Arte.

Universidad Autónoma de Ciudad Juárez. ISSN: 2448-900X 
formas de control social que se manifiestan de forma "multiescalar, y ello al menos en dos sentidos: uno, reconstituye relaciones a distintas escalas (regionales, nacionales, internacionales) entre actores institucionales y económicos, como los estados locales y el capital "financializado"; y dos, sustituye las lógicas regulatorias redistributivas por lógicas competitivas, al mismo tiempo que transfiere los riesgos y responsabilidades a las agencias, actores y jurisdicciones locales" (Theodore et al., 2009: 2) .

Esto ha centrado la atención en las formas materiales sintetizadas de la espacialidad urbana, muy a menudo dejando de lado sus cualidades más dinámicas, generativas, explicativas y relativas a su desarrollo. Lo anterior sucede porque el espacio era un ente infinito estructurado según las leyes matemáticas, construido gracias a la racionalización de las formas físicas. Es un espacio homogéneo, pensado desde una perspectiva inductiva (objetiva) con la finalidad de dar respuesta a presupuestos meramente formales y generar un mundo en donde las diferencias se redujeran lo más posible y en donde todos los hombres del mundo participaran de sus beneficios. Sin embargo, esta idea de espacio lo que ha provocado es una represión de lo espacial, así como una represión de la posibilidad de otras temporalidades, porque se acaban reproduciendo modelos anclados a una representación icónica e imágenes estáticas, que neutralizan las posibilidades de entender las especificidades de los lugares, lo cual homogeniza la escala de reproducción en términos de clase social.

Sin embargo, no es solamente la producción de imágenes la responsable de esta represión, sino también lo es la redefinición del espacio urbano, de acuerdo con los requisitos del nuevo patrón de acumulación de capital ya que, retomando a David Harvey, se refuerza la imagen de la ciudad mediante la organización de espacios urbanos espectaculares, lo cual se ha convertido en un medio para atraer capitales y personas (del tipo ideal) en el periodo (desde 1973) de competición interurbana intensificada y de empresarialismo urbano. Como también menciona Carlos Vainer (2000), los atributos espaciales necesarios para las ciudades que deseen participar en el mercado mundial de las ciudades globales requieren importantes inversiones y, en este contexto, el Estado está llamado a participar en la producción de la ciudad como una mercancía y debe ser gestionada como un negocio.

De esa forma, la reproducción del espacio en/de la ciudad, no sucede sin ofrecer nuevas posibilidades a los intereses políticos-económicos de determinada hegemonía, lo que al mismo tiempo implica ciertas contradicciones. Esta reproducción llega a las diferentes prácticas espaciales de la ciudad a partir de procesos y estrategias de ajuste del capital en ciertas áreas, las cuales se delimitan por la construcción de marcos institucionales que, aunque mejoran el rendimiento del sistema capitalista, aumentan las desigualdades urbanas y sociales de la ciudad. En este sentido, destaca que el orden es la renovación que se espacializa a través de intervenciones escalonadas, con el objetivo de transformar ciertas zonas en espacios imaginarios y espectaculares, alienados del contexto territorial en el que operan. A menudo, estos espacios no tienen características experimen-

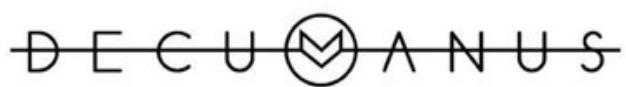

REVISTA INTERDISCIPLINARIA SOBRE ESTUDIOS URBANOS 
tales, sino solo visuales y relucientes cultivando una concepción del tejido urbano necesariamente fragmentada, lo que resulta en un palimpsesto de formas del pasado superpuestas unas a otras, o bien, un collage de usos corrientes, muchos de los cuales pueden ser efímeros.

Parece ser así que la ciudad pierde su sentido historicista frente a estos nuevos procesos de urbanización. Los lugares reciben nuevas identidades y el propio concepto de lugar pasa a tener alguna resistencia a su identidad, ya que como refiere Castells (1996), la sociedad-red construye una nueva espacialidad, donde los espacios de flujos predominan sobre los espacios de lugares, cambiando su forma, función y significado. Sin embargo, estas posturas pueden ser realmente cuestionables, ya que suprimen la desigualdad social que los mismos procesos han constituido y aniquilan su espacialidad, por lo que las diferencias espaciales pierden toda la posibilidad de autonomía por su arreglo discursivo en una secuencia temporal, al omitir mucho sobre la construcción de tiempo-espacios a través de las relaciones de poder social.

En América Latina la expansión de modelos hegemónicos de Europa, pero sobre todo de Estados Unidos, llevaron a los gobiernos llamados "progresistas" a asumir las consignas del progreso y la modernidad (bajo la óptica imperialista), incluso cuando su discurso ofrecía acabar con la doctrina neoliberal, apoyados por movimientos sociales y la población de bajos recursos. En palabras de Welti (1998), "la esperanza de cambiar la situación social (miseria y exclusión) resultado del ajuste estructural que se aplicó en todo el subcontinente, movilizaron a la población en apoyo a proyectos políticos que ofrecían dicho cambio. La utopía capitalista parecía desempolvarse y mover nuevamente el deseo por otro mundo". Sin embargo, lo que pasó fue un ajuste y un reafirmar de la economía capitalista neoliberal, y el caso de Brasil es un ejemplo claro de lo anterior como se puede notar en su necesidad de afirmarse globalmente mediante eventos internacionales como el mundial y los juegos olímpicos.

Pero en distintas escalas, la representación ideológica del espacio público se manifiesta en "el redesarrollo de frentes ribereños (Puerto Madero en Buenos Aires; Rivera Norte en Concepción, Chile); la refuncionalización de áreas ferroviarias, viejos aeropuertos o zonas industriales en declive (Puerto Norte en Rosario; Proyecto Retiro en Buenos Aires, el proyecto Tamanduatehy en Santo André, Brasil, o el proyecto Bicentenario en el Gran Santiago de Chile) o simplemente la expansión de zonas (Santa Fe en México o la zona del Canal de Panamá) son algunos ejemplos" (Cuenya, 2009: 231). Esas intervenciones justificadas por el discurso de la modernidad (entiéndase orden, libertad y derecho) se han vuelto un verdadero estado de guerra socialmente abierto, que oprime y destituye toda posibilidad de los grupos más vulnerables de reproducirse. Los proyectos de renovación urbana -emancipados desde el urbanismo moderno impulsado por Haussmann y los principios del higienismo- han implicado una modernización del espacio geográfico y un largo proceso de urbanización espacial con la reubicación de excedentes de capital, que modifican los espacios geográficos y, a su vez, los estilos de vida. En este sentido, los proyectos de infraestructura y renovación urbana son los principales

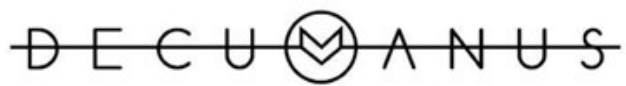

REVISTA INTERDISCIPLINARIA SOBRE ESTUDIOS URBANOS
Núm. 5. Vol. 5. Octubre 2019-Octubre 2020. Instituto de Arquitectura, Diseño y Arte.

Universidad Autónoma de Ciudad Juárez. ISSN: 2448-900X 
canales de ajuste que permiten el crecimiento urbano orientado al mercado, y al mismo tiempo una arquitectura (en términos literales) de control. Asimismo -como parte de los mismos principios de la modernidad-, las estrategias de renovación conllevan a la expulsión de los moradores, sobre todo de las clases trabajadores o populares, ya que constituyen una amenaza al orden social. Esto ha provocado lo que Harvey denomina "acumulación por despojo" (una dimensión fundamental del proyecto civilizatorio de la modernidad), con el objetivo de limpiar y ordenar los lugares, que esconde un verdadero proceso de encarcelamiento, pero también de militarización cada vez más regulados. Así, el espacio público de expresión política busca la riqueza y el poder que poco o nada tiene relación con su manifestación discursiva de democrático, plural e incluyente.

\section{Algunas conclusiones}

La reflexión establecida hasta el momento permite afirmar que el espacio público es una invención de la sociedad capitalista moderna, en su configuración espacial y que se establece desde el ámbito de la filosofía política como el espacio de las decisiones democráticas de la ciudad, o sea concernientes a toda la sociedad en un ejercicio de gobierno, donde supuestamente está incluida toda ciudadanía. Sin embargo, este estaba altamente confinado a determinado segmento de la sociedad (ciudadanos ilustrados), altamente excluyente, y que además enmarcado en cierta configuración arquitectónica, lo cual a su vez muestra cómo la ideología se establece desde lo que Harvey (2001) ha definido como spatial fixes, aquí no tanto como acumulación de capital, pero como forma de dominación y control social. Así, es importante tener presente el uso y las formas en que se hace uso del concepto, ya que su exhaustividad discursiva, tanto en el ámbito académico como político, no es neutral, pero ha sido estructurada en base a un mecanismo de supremacía que ha permitido legitimar y justificar una serie de actuaciones a distintas escalas, sobre la base de una "falsa" democracia, y que ha permitido alimentar los poderes hegemónicos.

En ese sentido, la carga ideológica que emana del espacio público visto como un producto de la sociedad capitalista moderna (a partir de las tres analogías constitutivas que se mencionan en el inicio) ha sido determinante en el nuevo urbanismo o el urbanismo neoliberal, pero también como un producto hegemónico que subyace a un propósito de control y dominación hacia América Latina. El espacio público, como elemento central de los procesos de desregulación ha sido importante para los monopolios extranjeros (tanto capital como financieros), así como para la disciplina del mercado, que se fija sobre todo en las principales capitales de los países latinoamericanos, donde se han llevado a cabo proyectos importantes de renovación urbana. Esto a su vez, parece contradictorio, ya que se incrusta en gobiernos que defienden una oposición al sistema neoliberal, en un discurso anti-neoliberalismo. Pero como bien comenta Foucault (2004: 157): "el problema del neoliberalismo, al contrario, pasa por saber cómo se puede ajustar el ejercicio global del poder político a los principios de una economía de merca-

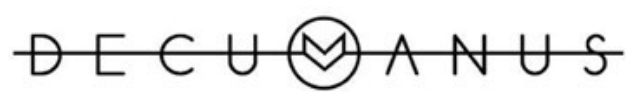

REVISTA INTERDISCIPLINARIA SOBRE ESTUDIOS URBANOS 
do. En consecuencia, no se trata de liberar un lugar vacío sino de remitir, referir, proyectar en un arte general de gobernar los principios formales de una economía de mercado", y en ese sentido se ha podido aliar a los gobiernos supuestamente llamados de izquierda. En este mismo proceso hay un retorno al espacio de forma ideológica por parte de la izquierda pero también desde la derecha conservadora, que se apropia de la negación de la política, reforzando una historia conservadora y democrática. Esto muestra la importancia de verlo desde dentro para que se pueda pensar en la representación de la izquierda en las propias estructuras internas de cambio desde sus contradicciones. Por lo anterior, puede afirmarse que hay un despliegue de la teoría como instrumento de politización que permite sustentar las prácticas establecidas desde los marcos internacionales de lo que debe ser la política urbana internacional y que muchas veces poco o nada tiene que ver con la realidad de América Latina. Esto ha generado mutaciones importantes en los procesos de reproducción y recomposición social de la ciudad generando una mayor segregación y exclusión social, así como una división y separación más aguda de clase y de los distintos grupos sociales. En esta línea de pensamiento las palabras de orden, tanto de gobiernos progresistas como de derecha, son renovación, reestructuración, regeneración y recualificación urbana, ya que se les considera instrumentos políticos e idearios hegemónicos que contribuyen a la cohesión social y a la integración de los sectores excluidos o vulnerables, capaces de contrarrestar la incontrolable fluidez y el desarraigo territorial del capitalismo tardío en distintas escalas espaciales (Filipe Narciso, 2018: 41). Cabe destacar que, incluso cuando la globalización neoliberal evoca la imagen de un proceso no diferenciado sin agentes geopolíticos claramente demarcados o poblaciones objetivas, en realidad oculta la alta concentración de las fuentes de poder de donde emana y fragmenta las mayorías a las que impacta (Massey, 2008). Esa ocultación es posible mediante intervenciones urbanas determinadas por discursos políticos ideológicos encauzados sobre una idea universal del y para el bien común; así, más que una realidad social es una idea reguladora hacia países dependientes, que en la práctica tiene la función de ocultar y neutralizar la dominación que ejerce, o pretende ejercer, al declarar que los intereses particulares de ese sector son idénticos, igualitarios y democráticos.

\section{Bibliografía}

Althusser, Louis (1980). Ideologia e aparelhos ideológicos do Estado (3. ed). Lisboa: Presença (Biblioteca universal presença; $\mathrm{n}^{\circ} 10$ ).

Ander Egg, Ezequiel (1998). Formas de alienación en la sociedad burguesa. Buenos Aires: Lumen-Humanitas.

Andreoli, Bruno (2014). Debates sobre la noción de esfera pública: ¿herramienta de emancipación o herramienta de dominación. Jornadas de Debate Feminista, organizadas por Cotidiano Mujer y la Red Temática de Género de la U de la R, Facultad de Ciencias Sociales. Montevideo, Uruguay, 4 al 6 de junio de 2014.

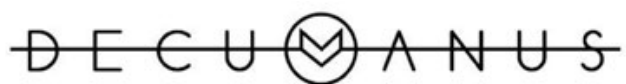

REVISTA INTERDISCIPLINARIA SOBRE ESTUDIOS URBANOS 
Arditi, Benjamin (2009, septiembre/diciembre). El giro a la izquierda en América Latina: ¿una política post-liberal? Ciências Sociais Unisinos 45(3): 232-246.

Arendt, Hannah (1972). La crise de la culture. París: Ideés/Gallimard.

Arendt, Hannah (1984). La vida del espíritu. Madrid: Centro de Estudios Constitucionales. Arendt, Hannah (1993). La condición humana. Barcelona: Paidós.

Ascher, Françoise (1995). Metapolis ou l'avenir des villes. París: Editions Odile Jacob.

Ascher, Françoise (2005). Los nuevos principios del urbanismo. Madrid: Alianza Editorial.

Baldwin, Peter (1999). Domesticating the Street. The Reform of Public Space in Hartford, 1850-1930. Columbus: Ohio State University Press.

Beltrán, Elena (1994). Público y privado: sobre feministas y liberales: argumentos en un debate acerca de los límites de lo político. Madrid: Doxa.

Borja, Jordi (2003). La ciudad conquistada. Madrid: Alianza Editorial.

Cantamutto, Francisco J. (2013, 15 de marzo). ¿Giro a la izquierda? Nuevos gobiernos en América Latina. RELACSO. Revista Estudiantil Latinoamericana de Ciencias Sociales, 2 [en línea]. http://relacso.flacso.edu.mx/giro-a-la-izquierda.

Castells, Manuel (1996). The Rise of the Network Society. Cambridge: Blackweel Publishers.

Cowen, Deborah (2014). The Deadly Life of Logistics. Mapping Violence in Global Trade. Minnesota: University of Minnesota Press.

Cuenya, Beatriz (2009, octubre). Grandes proyectos urbanos latinoamericanos. Aportes para su conceptualización y gestión desde la perspectiva del gobierno local. Cuaderno urbano. Espacio, cultura, sociedad [en línea]. http://www.redalyc.org/articulo. oa?id=369236769012

Duhau, Emilio y Ángela Giglia (2008). Las reglas del desorden: habitar la metrópoli. México: UAM-Azcapotzalco y Siglo XXI.

Echeverría, Bolívar. "Un concepto de modernidad", Transcripción del seminario La modernidad: versiones y dimensiones. http://www.bolivare.unam.mx/ensayos/Bolivar\%20 Echeverria- Un\%20concepto\%20de\%20modernidad.pdf.

Filipe Narciso, Carla (2018). Ideologías neoliberales y la compresión espacio tiempo: Analizando la configuración espacial escalar desde la producción del discurso político y las dinámicas socioespaciales en México. Revista Arquis, 7(2), pp. 40-49.

Foucault, Michel (2004). Nacimiento de la biopolítica. México: Fondo de Cultura Económica.

Fraser, Nancy (1991). Repensar el ámbito público: una contribución a la crítica de la democracia realmente existente. En C. Calhoun, Habermas and the Public Sphere (23-59). Cambridge: MIT Press.

Fraser, Nancy (1997). Iustitia Interrupta: Reflexiones críticas desde la posición "postsocialista". Bogotá: Siglo del Hombre Editores.

Giglia, Ángela (2003). Espacio público y espacios cerrados en la Ciudad de México. En P. Ramírez Kuri, Espacio público y reconstrucción de la ciudadanía (pp. 341-364). México: Flacso/Miguel Ángel Porrúa.

Goheen, Peter (1998). "Public Space and the Geography of Modern City". Progress in Human Geography, 4(22), pp. 479-496.

Gomes, Paulo (2002). A condição urbana: ensaios de geopolítica da cidade. Río de Janeiro: Bertrand Brasil.

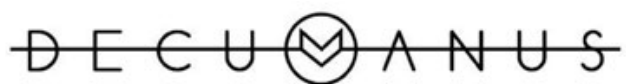

REVISTA INTERDISCIPLINARIA SOBRE ESTUDIOS URBANOS
Núm. 5. Vol. 5. Octubre 2019-Octubre 2020. Instituto de Arquitectura, Diseño y Arte.

Universidad Autónoma de Ciudad Juárez. ISSN: 2448-900X 
Habermas, Jürgen (1962). The Structural Transformation of the Public Sphere, Cambridge: Polity Press.

Habermas, Jürgen (1984). Mudança estrutural da esfera pública. Río de Janeiro: Tempo Brasileiro.

Harvey, David (1985). Urbanismo y desigualdad social (3.o ed.). Madrid: Siglo XXI, España. Harvey, David (1989). The Urban Experience. Oxford: Basil Blackweel.

Harvey, David (2001). Globalization and "Spatial fix". Geographische revue, pp. 23-30. https://publishup.uni-potsdam.de/opus4-ubp/frontdoor/deliver/index/docld/2251/ file/gr2_01_Ess02.pdf

Harvey, David (2006). The Political Economy of Public Space. En S. Low y N. Smith (eds.), The Politics of Public Space (pp. 17-34). Nueva York: Routledge.

Harvey, David (2007). Breve historia del neoliberalismo. Madrid: Akal.

Indovina, Francesco (2002). O espaço público: Tópicos sobre a sua mudança. Revista Ciudades. Comunidades e Territórios, 5: 119-123.

Lefebvre, Henri (1978). El derecho a la ciudad. Barcelona: Lito Fisan.

Massey, Doreen (2005). La filosofía y la política de la espacialidad: algunas consideraciones. En L. Arfuch (comp.), Pensar este tiempo: espacios, afectos, pertenencias, (pp. 101-128). Buenos Aires: Paidós.

Massey, Doreen (2008). Pelo espaço. Brasil: Bertrand.

Medina-Vicent, María (2013). Habermas y el feminismo. Encuentros y desencuentros entre la teoría crítica habermasiana y la teoría política feminista. Fórum de recerca, 18, pp. 3-26.

Pateman, Carole (1990). Críticas feministas a la dicotomía público/privado. En C. Castells (comp.), Perspectivas feministas en teoría política (pp. 31-52). Barcelona: Paidós.

Pradilla, Emilio (2009). Los territorios del neoliberalismo en América Latina. México: UAM-Xochimilco, Miguel Ángel Porrúa.

Pratt, Geraldine (1999). Geographies of Identity and Difference: Marking Boundaries. En D. Massey, J. Allen, P. Sarre (eds.), Human Geography Today (pp. 151-167). Cambridge: Polity Press.

Ramírez Kuri, Patricia (2009). Espacio público y ciudadanía en la Ciudad de México. Percepciones, apropiaciones y prácticas sociales en Coyoacán y su centro histórico. México: UNAM-IIS/PUEC / Miguel Ángel Porrúa.

Sennett, Richard (1978). El declive del hombre público. Barcelona: Anagrama.

Serpa, Ângelo (2004). Espaço público e acessibilidade: notas para uma abordagem geográfica. Geousp-Espaço e Tempo, 15, pp. 21-37.

Sierra, Natalia (2011). Los "gobiernos progresistas" de América Latina. La avanzada del posneoliberalismo. Aportes Andinos. Revista electrónica de derechos humanos Programa Andino de Derechos Humanos (PADH), 29, pp.1-17.

Smith, Neil (2005). El redimensionamiento de las ciudades: La globalización y el urbanismo neoliberal. En D. Harvey y N. Smith (coords.), Capital financiero, propiedad inmobiliaria y cultura (pp. 59-78). Barcelona: Museo de Art Contemporani de Barcelona.

Soja, Edward (1989). Postmodern Geographies: The Reassertion of Space in Critical Social Theory. London: Visa.

Soja, Edward (2009, septiembre). The city and spatial justice (La ville et la justice spatiale, trad. S. Didier y F. Dufaux). Justice spatiale/Spatial justice. http://www.jssj.org.

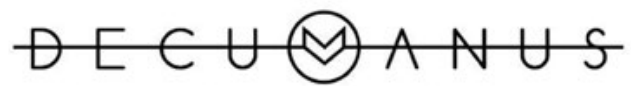

REVISTA INTERDISCIPLINARIA SOBRE ESTUDIOS URBANOS
Núm. 5. Vol. 5. Octubre 2019-Octubre 2020. Instituto de Arquitectura, Diseño y Arte.

Universidad Autónoma de Ciudad Juárez. ISSN: 2448-900X 
Theodore, Nik, Jamie Peck y Neil Brenner (2009, marzo). Urbanismo neoliberal: la ciudad y el imperio de los mercados. Temas Sociales, 66. Santiago de Chile: Ediciones SUR. http://www.sitiosur.cl/r.php?id=898.

Vainer, Carlos (2000). Patria, empresa e mercadoria. Notas sobre a estratégia discursiva do. Planejamento Estratégico Urbano. En O. Arantes, C. Vainer y E. Maricato. A cidade do pensamento único. Desmanchando consensos (pp. 75-103). Petrópolis RJ- Brasil: Vozes, Coleção Zero à Esquerda.

Young, Iris Marion (1996). "Vida política y diferencia de grupo: Una crítica del ideal de ciudadanía universal". En C. Castells (comp.). Perspectivas feministas en teoría política (pp. 99-126). Barcelona: Paidós.

Zukin, Sharon (2010). Naked City. The Death and Life of Authentic Urban Places. Nueva York: Oxford.

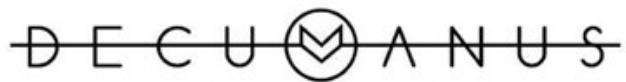

REVISTA INTERDISCIPLINARIA SOBRE ESTUDIOS URBANOS 